\title{
Fringe Benefits - Reflexos de sua Concessão nas Áreas Tributária e Trabalhista
}

\author{
Qearge Lippent ONeto \\ Advogado e Mestre em Direito Tributário pela USP.
}

IV

nicialmente cabe ressaltar que por fringe benefits, também chamado remuneração indireta, entende-se, genericamente, benefícios concedidos aos empregados de pessoas jurídicas e outra forma que não dinheiro.

Para fins do presente artigo o conceito a ser utilizado quando do tratamento do ponto atinente ao Imposto de Renda e Contribuição Social Sobre o Lucro da empresa é o corrente para esses tributos, qual seja: remuneração indireta se constitui nos pagamentos feitos a diretores e gerentes a título de despesas com aluguéis de imóveis para fins residenciais, contraprestação de arrendamento mercantil e/ou encargos de depreciação de automóveis de uso particular, pagamentos relativos a colégio para os filhos, despesas de conservação dos bens citados anteriormente, dentre outros.

\section{I - Encargos previdenciários}

\section{Legislação}

A previsão legal da matéria no âmbi. to previdenciário decorre de disposição do $\S 9$, do art. 28 da Lei $\mathrm{n}^{\mathrm{o}} 8.212 / 91$, que conceitua o salário-de-contribuição para fins de incidência da contribuição ao INSS. ${ }^{1}$

1. " art. 28. Entende-se por salário-de-contribuição:

I-para o empregado e trabalhador avulso: a remuneraçáo auferida em uma ou mais empresas, assim entendida a totalidade dos rendimentos pagos, devidos ou creditados a qualquer título, durante o mês, destinados a retribuir o trabalho, qualquer que seja a

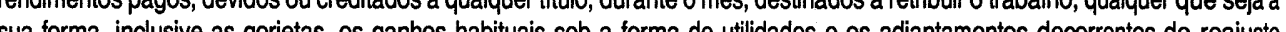
sua forma, inclusive as gorletas, os ganhos habluals sob a loma de unildades e os adlantamentos decorentes de reajuste salarial, quer pelos servicos eletivamente prestados, quer pelo tempo a disposiça do ampregador ou tomador do sen iços nos

$\S 9^{2}$ Não integram o salário-de-contribuiçăo para os fins desta Lei, exclusivamente:

a) os benefícios da previdência social, nos termos e limites legais, salvo o salário-maternidade;

b) as ajudas de custo e o adicional mensal recebidos pelo aeronauta nos termos da Lei $n^{2} 5.929$, de 30.10 .1973 .

c) a parcela in natura recebida de acordo com os programas de alimentaçäo aprovados pelo Ministério do Trabalho e da Previdência Social, nos termos da Lei in 6.321, de 14.04.1976.

d) as importâncias recebidas a título de férias indenizadas e respectivo adicional consitucional, inclusive o valor correspondente à dobra da remuneraçāo de férias de que trata 0 art. 137 da Consolidação das Lei do Trabalho - CLT; 


\section{Programa de alimentação ao trabalhador (PAT) e vale- transporte (VT)}

Conforme depreende-se do dispositivo legal supra mencionado, os valores pagos a estes títulos, VT e PAT, não integram o salário-de-contribuição para o INSS, des- de que concedidos conforme legislação própria de cada benefício.

\section{Ticket-combustível}

Os valores pagos a este título a gerentes integram o salário-de-contribuição a título de tributação pelo INSS.

\section{e) as importâncias:}

1. previstas no inciso I do art. 10 do Ato das Disposiçōes Constitucionais Transitórias;

2. relativas à indenização por tempo de serviço, anterior a 05 de outubro de 1988, do empregado não optante pelo Fundo de Garantia do Tempo de Serviço - FGTS:

3. recebidas a título da indenização de que trata 0 art. 479 da CLT;

4. recebidas a título da indenização de que trata 0 art. 14 da Lei $n^{2} 5.889$, de 08 junho de 1973;

5. recebidas a título de incentivo à demissão;

6. recebidas a título de abono de férias na forma dos arts. 143 e 144 da $\mathrm{CLT}$ :

7. recebidas a título de ganhos eventuais e os abonos expressamente desvinculados do saĺrio;

8. recebidas a título de licença-prêmio indenizada;

9 . rebica

9. recebidas a título da indenizaçáo de que trata 0 art. $9^{9}$ da Lei $n^{2} 7.238$, de 29

g) a ajuda de custo, em parcela única, recebida exclusivamente em decorrência de mudança de local de trabalho do empregado, g) a ajuda de custo, em parcela un

h) as diárias para viagens, desde que năo excedam a $50 \%$ (cinqüenta por cento) da remuneração mensal; h) as diárias para viagens, desde que não excedam a $50 \%$ (cinqüenta por cento) da remuneração mensal;

6.494, de 07 de dezembro de 1977;

1) o abono do Programa de Integração Social - PIS e do Programa de Assistência ao Servidor Público - PASEP

$\mathrm{m}$ ) os valores correspondentes a transporte, alimentação e habitação fornecidos pela empresa ao empregado contratado para trabalhar em localidade distante da de sua residência, em canteiro de obras ou local que, por força da atividade, exija deslocamento e estada, observadas as normas de proteção estabelecidas pelo Ministério do Trabalho;

n) a importância paga ao empregado a título de complementação ao valor do auxilio-doença, desde que este direito seja extensivo à totalidade dos empregados da empresa;

o) as parcelas destinadas à assistência ao trabalhador da agroindústria canavieira, de que trata 0 art. 36 da Lei $n^{2} 4.870$, de $1^{2}$ de dezembro de 1965;

p) o valor das contribuiçōes efetivamente pago pela pessoa juríica relativo a programa de previdência complementar, aberto ou fechado, desde que disponivel à totalidade de seus empregados e dirigentes, observados, no que couber, os arts. $9^{2}$ e 468 da CLT;

q) o valor relativo à assistência prestada por serviço médico ou odontológico, próprio da empresa ou por ela conveniado, inclusive o reembolso de despesas com medicamentos, óculos, aparelhos ortopédicos, despesas médico-hospitalares e outras similares, desde que a cobertura abrania a totalidade dos empregados e dirigentes da empresa:

r) o valor correspondente a vestuários, equipamentos e outros acessórios fornecidos ao empregado e utilizados no local do trabalho para prestação dos respectivos serviços:

s) o ressarcimento de despesas pelo uso de veiculo do empregado e o reembolso creche pago em conformidade com a logisla t) t) o valor relativa a plano educacional que vise a cduçaço báca, nos te 1996, e a cursos de capaclaçao e quallicaça profissionais vinculados as allidades desenvolvidas pela empresa, desde

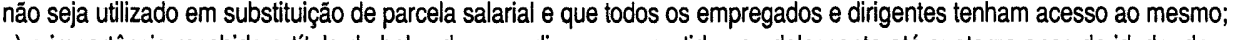
u) a importancia recebida a tifulo de bolsa de aprendizagem garantida ao com o disposto no artigo 64 da Lei no 8.069 , de 13 de julho de 1990;

x) o valor da multa prevista no $\$ 8^{2}$ do art. 477 da CLT." (grifo nosso)
Outrossim, deve ser ressalvado que, sendo comprovado que o referido benefício é utilizado única e exclusivamente para o exercício de sua atividade na empresa, tal montante não é tributado pelo INSS, com fulcro na Lei no 8.212/91, art. 28, § 9ㅇ, s.

\section{Jurisprudência}

A jurisprudência assim tem se manifestado sobre o assunto:

"SALÁRIO-DE-CONTRIBUIÇÃO - 1. O salário-de-contribuição é equivalente à remuneração efetivamente recebida a qualquer título, durante 0 mês, em uma ou mais empresas, para o segurado empregado. 2. Apelação improvida." (TRF $1 \stackrel{\text { a }}{\text { R. - AC }}$ 93.01.22395-3 - GO - 4a T. - Rel. Juiz Mário César Ribeiro - DJU 17.12.1998)

"AJUDA-ALIMENTAČ̃̃O DEPÓSITO EM CONTA-CORRENTE DOS FUNCIONÁRIOS DO BANCO DO BRASIL - NATUREZA JURÍDICA - ACORDO COLETIVO DO TRABA LHO - TÍQUETES - INCIDÊNCIA DA CONTRIBUIÇÃO PREVIDENCIÁRIA - PRELIMINARES - 1 . Preliminares que se rejeitam, uma ve que o Banco do Brasil não se desincumbiu do ônus da prova dos fatos constitutivos do direito alegado (art. 333 , I, do Código de Processo Civil - CPC). 2. Assertiva de nulidade do título executivo. Do Apelante o ônus de demonstra que o Apelado não teria satisfeito os requisitos insculpidos no inciso II, artigo 5, da Lei no ${ }^{\circ}$.830, de 22.09.1980, ou seja, que o INSS não teria feito constar no Termo de Inscrição da Dívida, o va lor originário daquela, o termo inicial e

2. Entendemos que a multa pode ser afastada caso a empresa opte pelo pagamento antes do início de fiscalizaçăo, por força do art. 138 do CTN. Entretanto, ressaltamos que este não e o entendimento na esfera administrativa. forma de calcular os juros de mora. 3 . Argüição de excesso de execução. Não logrou o Banco comprovar que o INSS não teria afastado do título executivo a parcelas referentes às glosas de salário maternidade. Ademais, na fase de liquidação, terá o Apelante, se o caso for, o ensejo de ver descontados os valores re lativos a essa rubrica, eis que obteve 0 reconhecimento desse direito, na via administrativa - 24/25. 4. 'A ajuda-alimentação creditada na conta corrente dos empregados do Banco não configura salário in natura, e sim, salário; sobre el incidirá a. contribuição previdenciária, nos termos do Regulamento do Custeio da Previdência Social. 5. Não-atendi mento às normas do Programa de $\mathrm{Ali}$ mentação do Trabalhador. Paga em dinheiro, mesmo sob o título de ajudaalimentação, é complemento de salário. Incidência da contribuição previdenciária'. Apelação improvida." (TRF 5 a R. - AC 137.999 (98.05.21178-9) - CE - 3 3 T. - Rel. Juiz Geraldo Apoliano - DJU 05.03.1999) (grifo nosso)

Assim, vislumbra-se que a jurisprudência também entende que os valores pagos a qualquer título aos empregados, salvo o expressamente previsto na legislação (vide item I, 1), integram o salário-de-contribuição destes, a título de incidência de INSS.

\section{Infrações Fiscais}

Em não oferecendo à tributação os valores pagos a título de fringe benefits, a empresa deveria regularizar a situação, me diante o recolhimento do imposto devido, com os encargos moratórios pertinentes, qual seja, multa ${ }^{2}$ e juros SELIC.

Revista da Faculdade de Direito da UFRGS, v. 18, 2000 


\section{II - Encargos trabalhistas}

A tendência da Justiça do Trabalho, no que tange aos benefícios, é entender que tudo o que se concede "para o trabalho" não é salário indireto, mas o que se dá "pelo trabalho" seria sim salário indireto, ou salá rio-utilidade como também é chamado.

Por óbvio que a diferenciação é muito tênue e decorre na maior parte de qua lado conseguir provar melhor os fatos.

Alguns benefícios, por sua alta prática nas relações trabalhistas, já tem enten dimentos mais claros, os quais resumidamente se transcreve abaixo:

\section{a) Alimentação}

a.1 Se a alimentação é dada de graça por força de lei, como na hipótese dos petroleiros e petroquímicos (Lei $\mathrm{n}$ ㅇ.5.811/72), é instrumento de trabalho e, como tal, não tem reflexo trabalhista nem tributário (art $458, \S 20$ da CLT). Ainda, quando o empregado trabalha fora da sua residência habitual, inclusive em frentes de trabalho, não há efeito salarial na concessão gratuita de alimentação, porque o trabalho seria impossível se não fosse concedida (Portaria SPS 2/79, item 39.2e). RCPS, art. 37, § 9o,$m$.

a.2 Se a alimentação é concedida de graça apenas para que o empregado possa fazer economia de salário, do que teria de gastar por conta própria, então a alimenta ção é salário para a Justiça do Trabalho.

a.3 Se a alimentação é cobrada, ela faz parte de um contrato paralelo ao de trabalho, de fornecimento de alimentação, e não tem efeito salarial, mesmo que a empresa cobre menos do que lhe custa. Já a entrega de vale-refeição tem caráter salarial, na forma do Enunciado TST n⿳⺈ 241, pela diferença entre o que a empresa paga e o que cobra.

a.4 O Decreto $\mathrm{n}$ o 5, de 14.01.1991, diz no art. $6^{\circ}$ que o valor da alimentação concedida dentro do programa de alimentação do trabalhador (PAT) não constitui remuneração, o que, de outra forma, já vinha declarado no art. $3^{\circ}$ da Lei $n^{\circ} 6.321 /$ 76 , tal programa também dá suporte fático de defesa na Justiça do Trabalho.

\section{b) Habitação}

b.1 Quando o fornecimento de habitação é indispensável ao trabalho, sem o que este não seria viável, constitui instrumento de trabalho, deve ser de graça, e, na regra do $\S 2^{\circ}$ do art. 458 da CLT, não é salário.

b.2 Se a habitação é fornecida gratuitamente apenas para economizar dinheiro do aluguel, é salário-utilidade para a justiça do trabalho.

b.3 Se a habitação é cobrada, passa a ser objeto de contrato de locação e perde efeitos trabalhistas.

\section{c) Transporte individual}

c.1 Se o fornecimento de condução pelo empregador é indispensável para que o serviço possa ser prestado, porque a empresa se encontra em local não servido regularmente pelo transporte público, inclusive frentes de trabalho, constitui um autêntico instrumento de trabalho, de modo que não há repercussão salarial.

c. $2 \mathrm{Se}$, entretanto, a condução gratuita objetiva dar economia a empregados que trabalham em região bem servida de transporte público, evitando que tenham de gastar com passagem, configura-se salárioutilidade para a Justiça do Trabalho.

c. 3 Cobrada, a condução passa a fazer parte de um contrato paralelo ao de trabalho, como fornecimento de condução, e não tem efeitos salariais, mesmo que a empresa cobre menos do que lhe custa, com exceção se puder encontrar fraude nessa prática, ou seja, que a diferença de custo do transporte tenha sido expressamente acertada para reduzir o valor do salário em dinheiro.

Em resumo:

Procura-se ao cobrar a utilidade, um ponto de equilíbrio, ou seja, fazer com que o preço seja baixo, para que represente um benefício ao trabalhador, mas não tanto que seja considerado simulatório, e, pois, nulo.

O nível adequado consiste no custo direto, isto é, a empresa transfere ao empregado a despesa exata do consumido ou usado, sem cobrar os gastos antecedentes, preparatórios, condicionantes nem conseqüentes. Assim por exemplo:

a) na habitação, se em imóvel da empresa, é cobrado o aluguel, mas não as despesas de condomínio, impostos, luz, água, manutenção, telefone;

b) na condução, se em veículo da empresa, é cobrado o combustível, mas não o salário do motorista, nem despesas de manutenção; se é alugado, o repasse é feito do custo do trajeto de ida e volta, e a empresa paga, em outra conta, a viagem da garagem até a empresa, as horas paradas, a comissão da empresa transportadora; não há reflexo salarial se a empresa fornece automóvel por empréstimo com todas as despesas pelo empregado, que assim arca com o custo do seu transporte, exceto nas hipóteses do art. 74 da Lei no 8.383/91;

c) na alimentação (se a empresa não preferir inserir-se no Programa de Alimentação do Trabalhador, caso em que a alimentação não é considerada salário in natura por força do art. $3^{\circ}$ da Lei $n^{\circ} 6.321$ / 76), é cobrado o custo do alimento, mas não o salário dos que preparam e servem as refeições, nem a energia elétrica, as instalações e limpezas particulares. Nesta linha de raciocínio, se a empresa concordava como uso pessoal, este uso configura salário indireto.

Para melhor ilustrar o entendimento da Justiça do Trabalho abaixo transcrevemos algumas jurisprudências, que seguem:

"SALÁRIO-HABITAÇÃO SALÁRIO IN NATURA - INTEGRA A REMUNERAÇÃO PARA TODOS OS EFEITOS LEGAIS - Tendo em vista o disposto no art. 458, da CLT, a habitação fornecida pelo empregador constitui salário in natura e integra a remuneração para todos os efeitos legais, pois, constitui-se em salário indireto." (TST - RR 103.504/94.7 - (Ac. 2.467) 94) - 5 T. - Rel. Min. Nestor Hein DJU 12.08.1994)

"SALÁRIO-UTILIDADE COMODATO - Salário in natura - Fornecimento de veículo - Comprovados nos autos que o veículo era cedido pela empresa recorrente a título de comodato, isto é, aquilo que é dado para a comodidade de alguém. A resposta ao quesito no 13 da perícia (fls. 152) e ao quesito $\mathrm{n}^{\circ}$ 
06 da ré (fls. 160), esclarecem a utilização que era feita do carro, tanto para o trabalho quanto para situações particulares. Nesta linha de raciocínio, se a empresa concordava como uso pessoal, este uso configura salário indireto." (TRT $1^{\mathrm{a}}$ R. - RO 34452/94 - 9a T. - Rel. Juiz Ideraldo Cosme de Barros Gonçalves DORJ 18.06.1996)

"AJUDA DE CUSTO COM BUSTÍVEL - NATUREZA SALARIAL - A ajuda de custo combustível, conce dida para a locomoção do empregado não possui natureza salarial, antes os termo do art. 457, § 20 da CLT." (TST - RR 158.006/95.9 - (Ac. 5.376/95) - 3 ${ }^{\mathrm{a}} \mathrm{T}$. Rel. Min. Roberto Della Manna - DJU 15.12.1995)

"AJUDA-QUILOMETRAGEM - NATUREZA - A ajuda-quilometra gem, que se traduz em reembolso de des pesas com combustível, em serviço, tem natureza indenizatória, não integrando o salário, ante os termos do art. 457, § 20 da CLT." (TST - RR 67.676/93.3 - (Ac. 342/94) - 2 T. - Rel. Min. Vantuil Abdala - DJU 08.04.1994)

Quanto aos cargos de confiança, o posicionamento da Justiça do Trabalho se inclina no sentido de que tais cargos não fazem jus à incorporação de seus benefícios aos seus salários, como se salário-utilidade fossem.

Importante esclarecer que para configurar o cargo de confiança a justiça exige, além do não-cumprimento de horário (re gistrar ponto) que o empregado tenha amplos poderes de mando, representação e substituição do empregador, que em suas funções repouse extrema confiança, que na prática dos seus atos se detecte claramente a responsabilização, orientação e supervisão que o coloquem em situação de superioridade diante de seu colegas de trabalho, e que haja diferenciação econômica nos salários daqueles cargos de confiança em relação aos demais.

As jurisprudências abaixo exemplificam bem as minúcias a que os juízes se prendem:

"CARGO DE CONFIANÇA Uma das características do cargo de confiança é o recebimento de ordem diretamente do próprio empregador e não através de intermediários." (TRT 1 a $\mathrm{R}$. - RO 03863/81 - 3르 T. - Rel. Juiz Luiz Augusto Pimenta de Mello - DORJ 29.07.1982)

CARGO DE CONFIANÇA UTILIDADE FORNECIDA PELO EMPREGADOR - Sendo o reclamante detentor de função de confiança, temse que a concessão de cota mensal de combustível cedida pelo reclamado nada mais é que meio para integral desempenho do cargo que lhe fora delegado, não representando nenhum plus que justifique a remuneração a título de salário, pois a sua natureza é meramente indenizatória. Recurso provido por unanimidade." (TRT 24ㄹ R. - RO 0001459 / 96 - (0000176/97) - Rel. Juiz João de Deus Gomes de Souza - DJMS 31.01.1997, p. 00018)

\section{III - Imposto de Renda e Contribuição Social Sobre o Lucro}

\section{Considerações gerais}

Conforme mencionado no início deste artigo, a legislação do Imposto de Renda considera como remuneração indireta (fringe benefits), os pagamentos feitos a diretores e gerentes a título de despesas com aluguéis de imóveis para fins residenciais, contraprestação de arrendamento mercantil e/ou encargos de depreciação de automóveis de uso particular, pagamento relativos a colégio para os filhos, despesas de conservação dos bens citados anterior mente, dentre outros, tendo tratamento tributário específico na legislação do Imposto de Renda e da Contribuição Social Sobre o Lucro Líquido.

\section{Base legal}

\subsection{IRPJ}

O Regulamento do Imposto de Renda (RIR/99), Decreto n 3.000/99, dispõe que:

“art. 358. Integrarão a remuneração dos beneficiários:

I - a contraprestação de arrendamento mercantil ou o aluguel ou, quando for o caso, os respectivos encargos de depreciação:

a) de veículo utilizado no transporte de administradores, diretores, gerentes e seus assessores ou de terceiros em relação à pessoa jurídica; ${ }^{3}$

b) de imóvel cedido para uso de qualquer pessoa dentre as referidas na alínea precedente;

II - as despesas com benefícios e vantagens concedidos pela empresa a administradores, diretores, gerentes e seus assessores, pagas diretamente ou através da contratação de terceiros, tais como:

a) a aquisição de alimentos ou quaisquer outros bens para utilização pelo beneficiário fora do estabelecimento da empresa;

b) os pagamentos relativos a clubes e assemelhados;

c) o salário e respectivos encargos sociais de empregados postos à dis posição ou cedidos, pela empresa, a administradores, diretores, gerentes e seus assessores ou de terceiros;

d) a conservação, o custeio e a manutenção dos bens referidos no inciso I.(...)"

Outrossim, tais despesas são mencionadas a título meramente exemplificativo (A legislação utiliza a expressão "tais como"). Assim, toda e qualquer remuneração, direta ou indireta, salvo se expressamente excetuada em legislação própria, como vale-transporte e PAT, comporá o salário dos dirigentes e gerentes.

\subsection{CSSL}

A Lei $\mathrm{n}$ 9 9.249/95, art. 13, dispõe:

"art. 13. Para efeito de apuração do lucro real e da base de cálculo da contribuição social sobre o lucro líquido, são vedadas as seguintes deduções:

(...)

II - das contraprestações de ar rendamento mercantil e do aluguel de

3. Nos casos de veículos, deve a empresa considerar como benefício indireto apenas o período em que o veículo fica em poder dos administradores, gerentes e assessores fora do horário de trabalho, como no período noturno e fins de semana, calculando, desta feita, as despesas pro rata, conforme PN 11/92, tratado adiante. 
bens móveis e imóveis, exceto quando relacionados intrinsecamente com a pro dução ou comercialização dos bens ou serviços;

III - das despesas de depreciação, amortização, manutenção, reparo, conservação, impostos, taxas, seguros e quaisquer outros gastos com bens móveis e imóveis, exceto se intrinsecamente relacionados com a produção ou comercialização dos bens ou serviços;

IV - das despesas com alimentação de sócios, acionistas e administrado res; $(. .)$.

Assim, as despesas pagas a título de alimentação, bem como as com bens mó veis e imóveis disponibilizados a sócios, diretores, acionistas e administradores, além de tributadas pelo Imposto de Renda, o deverão ser pela Contribuição Social Sobre o Lucro Líquido.

\section{Tratamento tributário dos fringe benefits}

As despesas referentes às remunerações indiretas para a pessoa jurídica terão o seguinte tratamento tributário, conforme dispõe o $§ 3^{\circ}$ do art. 358 do RIR/99:

"art. 358. Integrarão a remuneração dos beneficiários:

$$
\text { (...) }
$$

$\S 3^{\circ}$ Os dispêndios de que trata este artigo terão o seguinte tratamento tributário na pessoa jurídica:
I - quando pagos a beneficiários identificados e individualizados, poderão ser dedutíveis na apuração do lucro real;

II - quando pagos a beneficiários não identificados ou beneficiários identificados e não individualizados (art. 304), ${ }^{4}$ são indedutíveis na apuração do lucro real, inclusive o imposto incidente na fonte de que trata o parágrafo anterior."

Assim, sendo identificado o beneficiário de tais valores, o que significa dizer que tal montante integra seu salário, tais despesas serão dedutíveis para fins de Imposto de Renda e Contribuição Social Sobre o Lucro Líquido, havendo, ainda, retenção na fonte em nome do beneficiário, com base na tabela progressiva.

Caso não seja identificado o beneficiário, o RIR/99 preceitua:

$$
\text { "art. 358: (...) }
$$

$\S$ 1ํ A empresa identificará os beneficiários das despesas e adicionará aos respectivos salários os valores a elas correspondentes, observado o disposto no art. $622 . .^{5}$

$\S 2^{\circ}$ A inobservância do disposto neste artigo implicará a tributação dos respectivos valores, exclusivamente na fonte, observado o disposto no art. 675." ${ }^{\prime 6}$

Assim, sendo o beneficiário identificado, a tributação do Imposto de Renda ocorrerá na fonte, com base na tabela pro-

4. "art. 304. Não são dedutíveis as importâncias declaradas como pagas ou creditadas a titulo de comissōes, bonificações, gratificaçôes ou semelhantes, quando não for indicada a operação ou a causa que deu origem ao rendimento e quando o comprovante do pagamento não individualizar o beneficiário do rendimento."

5. Nestes casos haverá a incidência de INSS (20\%) e FGTS (8\%), bem como todos os outros reflexos trabalhistas.

6. "art. 675 . A falta de identificação do beneficiário das despesas e vantagens a que se refere 0 art. $622 \mathrm{e}$ a sua não incorporação ao salário dos beneficiários, implicará a tributação exclusiva na fonte dos respectivos valores, à alíquota de trinta e cinco por cento.

gressiva; caso contrário, o montante das despesas será tributado à alíquota de $35 \%$.

\section{Conceito de beneficiário}

Segundo o Parecer Normativo no $11 /$ 92 do Coordenador-Geral do Departamento da Receita Federal, a definição dos beneficiários dos fringe benefits (administradores, diretores, gerentes e seus assessores) é a seguinte:

"8.1 Administradores - Pessoas que praticam, com habitualidade, atos privativos de gerência ou administração de negócios da empresa, e o fazem por delegação ou designação de assembléia, de diretoria ou de diretor.

São excluídos desta conceituàção os empregados que trabalham com exclusividade, em caráter permanente, para uma empresa, subordinada hierárquica e juridicamente e, como meros prepostos ou procuradores, mediante outorga de instrumento de mandato, exercem essa função cumulativamente com a de seus cargos efetivos e percebem remuneração ou salário constante do respectivo contrato de trabalho, provado em carteira profissional.

8.2 Diretores - Denominação dada a toda pessoa que dirige ou administra um negócio ou soma determinada de serviços. Exercem a direção mais elevada de uma instituição ou associação civil, de uma companhia ou sociedade comercial, podendo ou não ser acionistas ou associados. Os diretores são, em

$\S 1^{2} 0$ rendimento será considerado líquido, cabendo o reajustamento do respectivo rendimento bruto sobre o qual recairá o imposto.

$\S 2^{\circ}$ Considera-se vencido o imposto no dia do pagamento da referida importância."

7. Para os outros empregados a lei prevê que tais valores devam ser parte integrante do salário. princípio, escolhidos por eleição em assembléias, nos períodos assinalados nos estatutos ou nos contratos sociais.

8.3 Sócio, Diretor ou Administrador - Empregado

Nos casos de sócio, diretor ou administrador que sejam, concomitantemente, empregados da empresa, os rendimentos auferidos, seja a título de remuneração como dirigente, seja como retribuição do trabalho assalariado, estão sujeitos, no seu total, aos limites e condições estabelecidos em lei.

9. Contudo, o art. 74 destina-se a um universo de pessoas mais abrangente do que os dirigentes definidos nos atos retromencionados, alcanserviços de assessoria aos administrado. res, diretores e gerentes.

(...)

Assim, deve-se entender que assessor é a pessoa que tenha subordinação direta e imediata ao administrador, gerente ou diretor, e atividade funcional ligada à própria atividade da pessoa as. sessorada."

Desta feita, conclui-se que a definição dos beneficiários dos fringe benefits abrange tanto os gerentes e diretores estatutários, seus assessores, bem como os empregados que estejam com seus contratos de trabalho suspensos em decorrência de terem assumido função estatutária de diretor. $^{7}$

Revista da Faculdade de Direito da UFRGS, v. 18,2000 çando, também, as pessoas que prestam 


\section{Dedutibilidade das despesas na pessoa jurídica}

A dedutibilidade das despesas das pessoas jurídicas está relacionada, a priori, que estas estejam intrinsecamente relacionadas com a produção ou comercialização dos bens e serviços. ta forma:

O RIR/99 explicita tal conceito des-

“art. 299. São operacionais as des pesas não computadas nos custos, neces sárias à atividade da empresa e à manutenção da respectiva fonte produtora.

$\S 1^{\circ}$ São necessárias as despesas pagas ou incorridas para a realização da transações ou operações exigidas pela atividade da empresa.

$\S 2$ 을 As despesas operacionais admitidas são as usuais ou normais no tipo de transações, operações ou atividades da empresa.
$\S 30$ O disposto neste artigo aplica-se também às gratificações pagas aos empregados, seja qual for a designação que tiverem."

Em suma, as despesas ditas normais da empresa são aquelas intimamente ligadas à atividade-fim da empresa e, desta forma, consideradas dedutíveis na apuração do Imposto de Renda (IRPJ) e da Contribuição Social Sobre o Lucro Líquido (CSSL), o que diferencia-se dos fringe benefits, os quais não guardam ligação com a atividade da empresa, como pagamento de despesas de colégio de diretores, aluguel de imóveis residenciais, etc.

Entretanto, estes últimos - fringe benefits -, quando atendidos certos requisitos legais, conforme anteriormente exposto, passam também a ser dedutíveis na pessoa jurídica.

\section{Harmonisation of the Tax Systems in Europe Judgements of the European Court of Justice}

\author{
Serhard Laule \\ Rechtsanwalt und Steuerberater, \\ Frankfurt/Main
}

\section{Introduction}

7 he founding treaty of the European Economic Community (EC Treaty) has as its objective the creation of an economic unit within which the free movement of goods, persons, services and capital is facilitated ${ }^{1}$. The establishment of this economic unit requires agreement on certain principles governing the inter-action of the tax systems of the member states and

Such harmonisation of European tax law as has been successfully achieved so far by the legislature by means of directives, which require to be incorporated into domestic law by each member state, relates only to indirect taxation ${ }^{3}$. Harmonisation thereby a certain degree of harmonisation ${ }^{2}$.

\author{
Orobext Webex \\ Rechtsanwalt, Frankfurt/Main
}

1. cf. Schmitt, IWB, Fach 11a, 363 ff.; Huschens, RIW 1999, 326 ff.

2. cf. Förster, in: Bleckmann, Europarecht, 6. Aufl., 717, 719; VoB, in: Dauses, Handbook of EU-WirtschaftsR, J Rn. 4.

3. This applies especially to Value Added Tax (VAT). Achievment of a common system of VAT (principle of transition from state of destination to state of origin) has, however, faded into the distant future (cf.: Dziadkowski, FS-Rädler, 1999, $137 \mathrm{ff}$.)

4. Cf. Art. $93,94 \mathrm{EC}$

5. Cf. in detail: Lang, FS-Flick, 1997, 873, 876; Klein, DStJG 19, 7, 23.

6. Voß, in: Dauses, Handbook of EU-WirtschaftsR, J Rn. 3; Förster, in: Bleckmann, Europarecht, 6. Ed. 717, 719.

of direct taxation by means of directives incorporated into national law is in its initial stages only. This may be due to the preconditions required for harmonisation, in particular, the European Council requirement of unanimity ${ }^{4}$, and the principle of subsidiarity which is particularly relevant to matters of direct taxation ${ }^{5}$. In addition, taxation is understood by each member state to be a characteristic of its sovereignty and protected as such. Taxation has an over-riding significance as the means of financing national budgets, and of determining economic policy. Taxation policy can also be an instrument of competition ${ }^{6}$. Recent studies show an increasing trend towards the use of taxation in competition

Revista da Faculdade de Direito da UFRGS, v. 18, 2000 